\title{
Psychometric evaluation of the Newcastle Satisfaction with Nursing Scales.
}

Piredda M, Vellone E, Piras G, Fida R, Latour JM, Matarese M, Alvaro R, De Marinis MG.

J Nurs Care Qual. 2015 Jan-Mar;30(1):84-92. doi: 10.1097/NCQ.0000000000000078.

\section{Accepted version}

\begin{abstract}
This study tested the psychometric properties of the Italian version of the Newcastle Satisfaction with Nursing Scales through Factor Analysis with 659 medical and surgical inpatients. One factor was found for the Scale Satisfaction and four factors for the Scale Experiences: Carelessness, Emotional support, Relationship/information, Caring times. This validation makes available to nurses and managers a multidimensional tool able to discriminate between different care experiences and to identify areas for care improvement.
\end{abstract}

Key words: Patient Satisfaction, Adult, Nursing Care, Psychometrics, Statistical Factor Analysis.

\section{INTRODUCTION}

In the last decades health scientific literature on patient satisfaction has grown exponentially. However, persisting lack of consensus on the definition of satisfaction and factors influencing clinical practice based on satisfaction results, hinders the possibility to measure it effectively. ${ }^{1,2,3}$ Measuring patient satisfaction is a complex task because of the multidimensional and subjective feature of satisfaction, which can have different meanings for different people. ${ }^{4}$ Thus, measures of this construct should be developed taking into account patients' views and should be multidimensional, valid and reliable if they are to help clinicians to improve the quality of care. 
Patient satisfaction is often linked to measures of quality improvement. Since the seminal work by Donabedian, ${ }^{5,6}$ satisfaction has become an important measure of care quality that gives information on how customer's values and expectations are met. According to Donabedian, patient satisfaction is the patient's judgment on aspects of the quality of care. ${ }^{7}$ Accordingly, patient satisfaction is increasingly used in many hospitals as a quality performance indicator. ${ }^{8}$

In evaluating patient satisfaction many personal variables are involved such as cultural, socio demographic, cognitive, affective and experiential ones. In fact, satisfaction depends on personal expectations and dispositions, as well as previous care experiences and length of hospital stay. ${ }^{4}$ Thus, it does not necessarily judge the technical and medical quality of the care received. Moreover, satisfaction, from the Latin word "satis" meaning enough, is a relative concept that implies only adequate care. While patient dissatisfaction means that health care has not achieved its goal, patient satisfaction does not always imply excellent or high quality care. In other words, patient satisfaction is a necessary but not sufficient condition of quality care.

Studies combining quantitative and qualitative methods show positive satisfaction scores even for objectively negative experiences, as patients attribute the poor care received to causes which are not in the control of the healthcare providers or the services they are evaluating. ${ }^{9}$ As a consequence, many surveys on patient satisfaction convey high ratings ${ }^{1}$ and are often unable to document variations between different standards of care ${ }^{10}$. In particular, measures of patient satisfaction tend to be more positive and more influenced by patients' characteristics than the report of care experiences. ${ }^{11}$ Thus, ratings of patients' experiences are more useful than subjective questions about satisfaction in order to discriminate between care performances. The combination of satisfaction and experiences surveys can get a wider and truer picture of the patient's judgment of the care received. ${ }^{12,13}$ 
Nursing care has a direct relationship with and is the most important predictor of the overall satisfaction with health care. ${ }^{14}$ Patient satisfaction with nursing has been defined as "the degree to which nursing care meets patients expectations in terms of art of care, technical quality, physical environment, availability and continuity of care" ${ }^{, 5(\mathrm{p} .226)}$ and relates to the quality of nursing care. ${ }^{16,17}$ Several factors can influence patient satisfaction with nursing care such as patient characteristics and expectations, nurse-patient relationship and nurse competence, and organizational or physical environments. ${ }^{18}$ However, as for general satisfaction with healthcare, there is no general agreement in the literature on the factors that constitute patient satisfaction with nursing. In particular, it is difficult to identify which factors influence Italian patients' satisfaction with nursing because Italian studies on this topic are sparse and have been conducted with general surveys of hospital satisfaction or using instruments not tested for validity and reliability. ${ }^{19,20,21}$ Additionally, it is difficult to identify specific tools for the measurement of patients' satisfaction regarding nursing care only. Available questionnaires often do not measure exclusively satisfaction with nursing care, but are often associated with the evaluation of general health services. Therefore, these surveys are relatively useful to identify critical points of nursing care. In addition, nursing care can be delivered in different settings with dissimilar care characteristics that can affect the perception of patient satisfaction. Therefore, instruments designed to measure patient satisfaction should be specific for nursing care and for each specific setting to allow the results to change clinical practice. ${ }^{22,23}$ Satisfaction instruments should also be valid, reliable and, according to the subjective and multidimensional nature of satisfaction, developed taking into account patients' views and multidimensional. ${ }^{1}$ The instruments should also be able to reveal differences between ways of care delivery, in order to influence the process of care evaluation. ${ }^{12}$

A review of the literature revealed that no Italian studies are reported on psychometrically sound instruments measuring adult medical-surgical inpatient satisfaction with nursing. ${ }^{1,18,24}$ However, 
several non-Italian satisfaction instruments were identified, such as the "Patient Satisfaction with Nursing Care Quality Questionnaire" (PSNCQQ), which is patient-centered, specific for medicalsurgical inpatients and had excellent psychometric properties. ${ }^{25}$ Unfortunately the PSNCQQ is onedimensional and only allows for the rating of satisfaction and not both experience and satisfaction ratings. Another instrument identified was the Patient's Assessment of Quality Scale-Acute Care Version (PAQS-ACV). ${ }^{23}$ The PAQS-ACV has been developed from qualitative interviews with medical and surgical patients admitted in hospital, it has been psychometrically tested and includes 45 items on 5 factors, the number of items in each factor ranged from 2 to 17 . However, after development the instrument was used only in one pilot study, ${ }^{26}$ and seemingly does not collect both experiences of and satisfaction with nursing.

The instrument identified with the preferred characteristics for our study in Italy is the "Newcastle Satisfaction with Nursing Scales" (NSNS). The NSNS was developed with medical-surgical inpatients' as expert informants about the quality of the care received. ${ }^{27,28}$ It showed good validity and permitted to discriminate the quality of the care received between different hospitals and wards. ${ }^{29,30}$ The NSNS has also the advantage of evaluating both the patients' satisfaction with and the experiences of nursing care in hospital settings. In addition, it allows respondents to add open comments on the perceived experience and to rate 2 overall questions about satisfaction on the hospital stay and on nursing care. The NSNS has been translated and used in several countries. ${ }^{31-35}$

Our research team translated the NSNS into Italian and tested face and content validity and reliability in a pilot study. ${ }^{24}$ Internal consistency resulted in a Cronbach's alpha of .95 , similar to previous studies ranging between $.91-.96 .^{30,32,34}$ The NSNS Italian version showed preliminary validity and reliability comparable to the original and other translated versions. ${ }^{24}$

The developers of the NSNS performed factor analyses that showed one factor for each scale. ${ }^{30}$ 
Construct validity was further evaluated making a priori predictions by Peterson et al. ${ }^{35}$ However, to date no study explored construct validity with factor analysis of the NSNS after its development. The aim of this study was to further test the psychometric properties of the Italian version of NSNS by assessing construct validity through exploratory and confirmatory factor analysis.

\section{METHODS}

\section{Sample and setting}

The study was carried out in 14 medical and surgical wards of 3 secondary hospitals belonging to the same Local Health Centre (ASL) in the Italian region of Sardinia. Consecutive patients admitted to the selected wards over 12 months were recruited when they met the following inclusion criteria: aged 18 years or older, who spent 2 or more nights in the hospital and who were able to read and write Italian. Severely ill patients or mentally disabled patients not able to complete the questionnaire were excluded.

\section{Ethical considerations}

The study was approved by the Ethical Committee of the Local Health Centre and by the General Directions of the hospitals involved.

\section{Instruments}

Permission to use the NSNS was granted by the authors. The NSNS is a self-completed questionnaire, which incorporates 2 different scales and a final section.

The "Experiences of nursing scale" includes 26 statements describing experiences of nursing care using a 7-point Likert scale (from 1: disagree completely to 7: agree completely). In order to avoid affirmation bias and response set, they contain a combination of positively and negatively phrased statements (15 and 11 items respectively). 
The "Satisfaction with nursing scale" includes 19 items on aspects of nursing care rated on a 5-point Likert scale (from $1=$ not at all satisfied, to $5=$ completely satisfied).

The final section elicits patient demographic information and details of the hospital stay. It contains also 2 items of overall satisfaction with nursing care and with hospital stay that allow 7 possible answers scored from 1=dreadful, to $7=$ excellent. Finally, the instrument provides space for open remarks on the hospital experience and the nursing care received.

\section{Data collection}

Nurse managers and staff nurses provided the names of patients who met the inclusion criteria and were potentially close to discharge. Researchers not involved with care approached eligible patients and orally informed the patients and handed over the information letter including the questionnaire. Patients completed the questionnaire the day before discharge and returned it in a sealed box placed at the entrance of the ward. The data collection took place between February 2009 and January 2010.

\section{Data analysis}

Descriptive analyses of socio-demographic variables of the sample were calculated. Normality of the items of the NSNS was ascertained considering both skewness and kurtosis indices. The dimensionality of both scales of the Italian version of the NSNS was investigated first by mean of Exploratory Factor Analysis (EFA); then the resulting factor solution was validated through Confirmatory Factor Analysis (CFA). Preliminary Kaiser-Meyer-Olkin (KMO) and the Bartlett's test of sphericity were used to examine the factoriability of the data. With regard to the EFA, Principal Axis Factoring was used as a method of parameters estimation with an oblique rotation. CFA was then used to cross-validate the factor structure. Since some of the items were not normally distributed we used Mplus MLMV 
(Maximum Likelihood with Missing Values) as method of parameters estimation, which corrects standard errors as well as the chi-square test statistic for non-normality. The model fit was tested using Chi-square $\left(\chi^{2}\right)$, the Comparative Fit Index (CFI), the Root Mean Square Error of Approximation (RMSEA) and the Standardized Root Mean Square Residual (SRMR). The quality of the factors was then analyzed through the factor score determinacy coefficients and reliability through Cronbach's Alpha Coefficient. Correlation between the scores of the resulting factors and the overall assessment of nursing care and of hospital stay was evaluated by Pearson' correlation coefficient. Significance was set at $<0.05$. Statistical analyses were performed using SPSS 19.0 (IBM Corp. Armonk, NY, USA) and Mplus 7.1 (Muthén and Muthén, Los Angeles, CA, USA).

\section{RESULTS}

In the 12 months study period, 775 patients were invited to participate and 659 (85\%) patients completed the questionnaires. Of the respondents, $51.7 \%(\mathrm{n}=341)$ were male. Mean age was 54.3 years (range: 18-96; SD 17.8). The majority of the sample (54\%) completed only primary or secondary school, $35.6 \%$ were high school graduates and $10.4 \%$ had a university degree. The mean length of stay for hospital wards was 7.1 days (range: $3.3-10$, SD 2.2).

\section{Construct validity and reliability of the "Experiences of nursing scale"}

Bartlett's test of sphericity resulted significant $\left(\chi^{2}=(325) \mathrm{df}=6152, \mathrm{p}<0.001\right)$ and the KMO index of sampling adequacy was 0.92. Based on these results the data set of the Experiences of nursing scale was considered suitable for a factor analysis. Indices of skewness and kurtosis revealed that all the items were not normally distributed with these indices higher than $|1|$. With regards to the EFA, in line with the scree-plot of eigenvalues and the simplicity criteria (the first ten eigenvalues were: $7.63,2.93,1.38,1.26,0.98,0.93,0.85,0.79,0.77,0.67)$ of the Experiences of nursing scale 4 factors were extracted, that explained about $42 \%$ of the total variance. Factor 1, labeled 
Carelessness, was loaded by 9 items and explained $14 \%$ of the total variance. Factor 2, labeled Emotional support, was loaded by 6 items and explained $12 \%$ of the total variance. Factor 3 , labeled Relationship and information, was loaded by 6 items and explained $10 \%$ of the total variance. Finally Factor 4, labeled Caring times, was loaded by 5 items and explained $6 \%$ of the total variance (Supplemental Digital Content, Table 1). Results of the CFA also confirmed the 4factor solution with an acceptable fit to the data $\chi^{2}(293)=731.32, \mathrm{p}<0.01 ; \mathrm{CFI}=90 ;$ RMSEA $=$ 0.048 (CI: $0.044-0.053), \mathrm{p}=0.74 ; \mathrm{SRMR}=0.05$ (Supplemental Digital Content, Table 1). Also the factor score determinacy indices (Supplemental Digital Content, Table 1) confirmed the goodness of the factor structure. The correlations between Factors were: -.465 (Factor 1 and 2); 0.358 (Factor 1 and 3); .603 (Factor 1 and 4); Factor 2 and 3 (0.685); Factor 2 and 4 (-.568) and between Factor 3 and 4 (-.464). The Cronbach's Alpha Coefficients ranged from .60 for the factor Caring times to .87 for the factor Carelessness (Supplemental Digital Content, Table 1).

\section{Construct validity and reliability of the "Satisfaction with nursing scale"}

Estimates of the Bartlett's test of sphericity were significant $\left(\chi^{2}=(171) 12605, \mathrm{p}<0.001\right)$ and KMO index of sampling adequacy was .98. Based on these results the data set of the Satisfaction with nursing scale was considered suitable for a factor analysis. Indices of skewness and kurtosis revealed that all the items were normally distributed with these indices lower than $|1|$.

With regards to the EFA in line with the scree-plot of eigenvalues (the first ten eigenvalues were: $13.01,0.90,0.59,0.53,0.45,0.43,0.39,0,33,0,33,0,30)$ we decided to extract one factor of the Satisfaction with nursing scale. This factor explained more than $68 \%$ of the total variance and was labeled Satisfaction with nursing. As shown in Supplemental Digital Content, Table 2 all items loaded above 0.74 . Results of the CFA also confirmed the one-factor solution with an acceptable fit to the data $\chi^{2}(144)=599.65, \mathrm{p}<0.01 ; \mathrm{CFI}=97 ; \mathrm{RMSEA}=0.071$ (CI: $.065-$ 0.076), $\mathrm{p}<0.01 ; \mathrm{SRMR}=0.02$ (Supplemental Digital Content, Table 2). Also the factor score 
determinacy indices confirmed the goodness of the factor structure. The Cronbach's Alpha value was .98 (Supplemental Digital Content, Table 2).

The correlations of the 4 factors of the scale Experiences of nursing and of the Satisfaction with nursing dimensions with the overall assessment of nursing care and the overall assessment of the hospital stay (Table) were all significant $(\mathrm{p}<.01)$. These results indicated that the higher the emotional support, relationship and information, caring times and satisfaction with nursing and the lower the carelessness the higher the overall satisfaction with both nursing care and hospital stay.

\section{DISCUSSION}

The aim of this study was to test the psychometric properties of the Italian version of the NSNS. The evaluation of construct validity found several factors that constitute the NSNS scales. Factor analysis of the scale "Satisfaction with nursing" showed a single factor labeled Satisfaction with nursing that explains alone $68.6 \%$ of the total variance of the items. This is consistent with the factor analysis performed by the authors of the original instrument, ${ }^{30}$ which found that all items of the scale were highly interrelated. It configures a one-dimensional scale which measures patient' satisfaction in regards to different aspects of nursing care. This may reflect the fact that satisfaction tends to be a global judgment about the care received, unable to discriminate between different aspects of care. ${ }^{36}$

In contrast, our factor analysis of the scale Experiences of nursing clearly identified that the perceptions of the experience of nursing cluster around 4 different factors, mirroring the multidimensional nature of the experience of nursing care. Therefore this study, unlike the one from the original authors of the instrument, ${ }^{30}$ was able to highlight different aspects of the nursing experiences perceived as important by patients: Carelessness, Emotional support, Relationship and information and Caring times. Carelessness refers to nurses' lack of caring which manifest through careless behaviors. Caring times 
relates to the nurses' time required by patients to satisfy their needs. Relationship and information refers to interpersonal relationships, which allow a positive atmosphere in the ward, and to the satisfying of patient' information needs. Emotional support relates to nurses' caring behaviors, which comfort patients and give them the attention they need. Carelessness and Caring times, seem to make evident whom the patient is and how he wants to be considered. Relationship and information and Emotional support indicate what patients want nurses to do for them.

The 4 factors identified in our study are often present in the literature on satisfaction with nursing care. For instance, among the defining attributes of this concept, Mahon ${ }^{37}$ identified interpersonal manner, communication abilities, information gathering and information giving. The factor Caring times is consistent with the empirical referent found by Mahon $^{37}$ for the concept of patient satisfaction Time spent with patients. The factors Emotional support and Relationship and information, are common to the Cox Interaction Model of Client Health Behavior. ${ }^{38}$ This model has been used with some frequency, ${ }^{39}$ including to analyze the concept of patient satisfaction. ${ }^{40}$ All factors identified in our study are consistent also with the findings of qualitative studies exploring adult patients perspectives on quality nursing care in acute care hospitals. ${ }^{41,42}$ Here, among the factors perceived by patients affecting the quality of care were patient information, nurse-patient relationship, having sufficient time to meet patient' needs, nurses being there when needed, nurses' personality or attitudes, empathy and compassion, needs not being met or delay in care.

There was a statistically significant correlation between the scores of the factors of the scales Experiences of nursing, the factor Satisfaction with nursing and the overall assessments of nursing care and hospital stay. These results add to the evaluation of the construct validity of the NSNS and are consistent with those obtained by Peterson et $\mathrm{al}^{35}$ who used the NSNS, and by Akin and Erdogan ${ }^{32}$ who used only the Satisfaction with nursing scale. However, in our study the dimension Carelessness was 
negatively correlated with Satisfaction with nursing and the global satisfaction scores. This differs from the study by Peterson et $\mathrm{al}^{35}$ where factor analysis was not carried out and the scale Experiences of nursing was correlated as a whole with the global satisfaction scores. In our study the scores of the negative items included in the dimension Carelessness were not reversed as in the other studies that used NSNS and this explains their negative correlation with the Satisfaction with nursing scores. In fact, the items that constitute the factor Carelessness are negative because these are statements that describe careless behaviors of the nurse such as taking no interest in patients as persons or favoring some patients over others. Thus, it makes sense that when they increase, patient satisfaction may decrease and vice versa.

Our results suggest that patient' experience of nursing care is multifaceted, complex and arises from different dimensions of care. The NSNS has the advantage of combining both ratings of satisfaction and experiences thus providing meaningful information on the patient's judgment of the care received. ${ }^{12}$ These ratings are able to discriminate between different aspects of care, and to identify those that need to be tackled in order to improve care. Nurse leaders could share the patients' ratings with staff nurses and encourage them to discuss both positive and negative patients' experiences. Data from NSNS surveys can therefore be used to monitor the quality of the care provided and to target practice improvements and learning opportunities aimed to those specific aspects of care with lower ratings. For example, in case of low scores of Caring times, nurse leaders could ensure more appropriate nurse-patients ratios and learning opportunities focused on patient-centered care. ${ }^{43}$ Moreover, the factors extracted in our study underline the patients' need to be acknowledged as a unique person, with individual needs and times to be satisfied. Recognizing the patient as a person can facilitate an interpersonal relationship including emotional support.

\section{Limitations}


This study has several limitations. The use of an intentional sample limits the generalizability of results. Eligible patients were given time to think about their participation in the study, however this time was limited by the proximity of discharge. Maybe some patients might feel a sense of coercion to participate particularly at this vulnerable time.

Although the aim of EFA is not to explain the variance of the items but to understand the structure of correlations among the items, the low explained variance of the factors of the scale Experiences with nursing care can be a limitation of the instrument together with the not so high reliability coefficient of the Caring Times factor of the scale. Future study should examine whether in the Italian context it can be useful to add questions that can better explore this factor.

The completion of the questionnaire prior to discharge certainly enhanced response rates. However, the timing of the survey could have an impact on patient' ratings. ${ }^{43}$ Questionnaires were administered when patients were close to discharge but still hospitalized and thus probably in worse health conditions and more dependent on their care providers than after discharge. ${ }^{44}$ The patient's physical condition, their vulnerability and tendency to social desirability of responses might have influenced the quality of the responses.

Some patients have shown difficulty completing the scale Experiences of nursing for various reasons. The first is due to the structure of the questionnaire, with negative statements and answers with reversed polarity. Thus, for some patients it turned out to be long and difficult to understand. It probably occurred to a greater extent than when the NSNS was developed as a result of the recent reduction of the length of hospital stays in Europe and the increased severity and complexity of care for patients admitted to hospitals. ${ }^{45}$ Therefore, for the severely ill patients who are currently admitted to acute wards, it would probably be more appropriate to administer satisfaction surveys when they return 
home, feel better and have sufficient time to reflect on their hospital stay.

\section{CONCLUSION}

The results of psychometric testing show that the Italian version of the NSNS is a valid measure of patient satisfaction with nursing and of the dimensions constituting patient' perception of care experience. Therefore, this study offers a useful tool for monitoring the views on the nursing care provided to adult Italian patients admitted to medical and surgical wards. The instrument can identify critical issues that need to be faced for the continuous improvement of nursing care and increase nurses' contribution to inpatient care quality.

The use of the NSNS may help nurses valuing patient perceptions of nursing care as a multidimensional phenomenon and to enhance their consideration of the patient as a unique person, worthy of an individualized and caring assistance. 


\section{REFERENCES}

1. Hawthorne G. Review of patient satisfaction measures. Canberra: Australian Government Department of Health and Ageing; 2006.

2. Latour JM, Hazelzet JA, van der Heijden AJ. Parent satisfaction in pediatric intensive care: A critical appraisal of the literature. Pediatr Crit Care Med. 2005;6(5): 578-584.

3. Latour JM, van Goudoever JB, Hazelzet JA. Parent satisfaction in the Pediatric ICU. Pediat Clin North Am. 2008;55(3):779-790.

4. Crow R, Gage H, Hampson S, Hart J, Kimber A, Storey L, et al. The measurement of satisfaction with healthcare: implications for practice from a systematic review of the literature. Health Technol Assess. 2002;6(32):1-244.

5. Donabedian A. Evaluating the quality of medical care. Milbank Mem Fund Q. 1966;44(3):166-203.

6. Donabedian A. The definition of quality and approaches to its assessment. Explorations in quality assessment and monitoring. Ann Arbor: Health Administration Press; 1980.

7. Donabedian A. The quality of care: how can it be assessed? JAMA. 1988;260(12):1743-8.

8. Jha AK, Orav EJ, Zheng J, Epstein AM. Patients' perception of hospital care in the United States. N Engl J Med. 2008;359(18):1921-31.

9. Heidegger T, Saal D, Nuebling M. Patient satisfaction with anaesthesia care: What is patient satisfaction, how should it be measured, and what is the evidence for assuring high patient satisfaction? Best Pract Res Clin Anaesthesiol. 2006;20(2):331-346.

10. Salisbury C, Wallace M, Montgomery A. Patient experience and satisfaction in primary care: secondary analysis using multilevel modelling. BMJ. 2010;341: c5004.

11. Schneider H, Palmer N. Getting to the truth? Researching user views of primary health care. Health Policy Plan. 2002;17(1):32-41.

12. Haggerty JL. Are measures of patient satisfaction hopelessly flawed? BMJ. 2010;341:c4783.

13. Schwarzkopf D, Behrend S, Skupin H, Westermann I, Riedemann NC, Pfeifer R, et al. Family 
satisfaction in the intensive care unit: a quantitative and qualitative analysis. Intensive Care Med. 2013;39(6):1071-9

14. Bjertnaes OA, Sjetne IS, Iversen HH. Overall patient satisfaction with hospitals: effects of patient-reported experiences and fulfillment of expectations. BMJ Qual Saf. 2012;21(1):39-46.

15. Mrayyan MT. Jordanian nurses' job satisfaction, patients' satisfaction and quality of nursing care. Int Nurs Rev. 2006;53(2):224-30.

16. Aiken LH, Sermeus W, Van den Heede K, Sloane DM, Busse R, McKee M, et al. Patient safety, satisfaction, and quality of hospital care: cross sectional surveys of nurses and patients in 12 countries in Europe and the United States. BMJ. 2012;344: e1717. doi: 10.1136/bmj.e1717

17. You LM, Aiken LH, Sloane DM, Liu K, He GP, Hu Y. et al Hospital nursing, care quality, and patient satisfaction: cross-sectional surveys of nurses and patients in hospitals in China and Europe. Int J Nurs Stud. 2013;50(2):154-61.

18. Johansson P, Oléni M, Fridlund B. Patient satisfaction with nursing care in the context of health care: a literature study. Scand J Caring Sci. 2002;16(4):337-44.

19. Marsullo M, Tozzi S, Biagini S, Rinaldi L. Estimating the grade of patient satisfaction at the bone marrow transplantation department in Florence hospitals. Assist Inferm Ric. 2000;19(2):120-5.

20. Mosconi P, Groth N, Apolone G, Niero M, Oprandi N, Belloli A, et al. Development and validation of a questionnaire measuring hospital consumer satisfaction. Ann Ig. 2003;15(4):34162.

21. Piras A, Poddigue M, Angelucci E. Patient satisfaction with nursing staff in bone marrow transplantation and hematology units. Transplant Proc. 2010;42(6):2257-63.

22. Yellen E. The influence of nurse-sensitive variables on patient satisfaction. AORN J. 2003;78(5):783-793.

23. Lynn MR, McMillen BJ, Sidani S. Understanding and measuring patients' assessment of the 
quality of nursing care. Nurs Res. 2007;56(3):159-66.

24. Piredda M, Cossu L, Amato S, Alvaro R, Tartaglini D, Spiga F, et al. A measure of patient satisfaction with Nursing care: the Italian version of "Newcastle Satisfaction with Nursing Scales”. International Nursing Perspectives. 2007;7(2-3):25-31.

25. Laschinger HS, Hall LM, Pedersen C, Almost J. A psychometric analysis of the patient satisfaction with nursing care quality questionnaire: an actionable approach to measuring patient satisfaction. J Nurs Care Qual. 2005;20(3):220-30.

26. Roszell S, Jones CB, Lynn MR. Call bell requests, call bell response time, and patient satisfaction. J Nurs Care Qual. 2009;24(1):69-75.

27. Priest J, McColl E, Thomas L, Bond S. Developing and refining a new measurement tool. Nurse Res. 1995;2(4):69-81.

28. Thomas LH, MacMillan J, McColl E, Priest J, Hale C, Bond S. Obtaining patients' views of nursing care to inform the development of a patient satisfaction scale. Int J Qual Health Care. 1995;7(2):153-63.

29. McColl E, Thomas L, Bond S. A study to determine patient satisfaction with nursing care. Nurs Stand. 1996;10(52):34-38.

30. Thomas LH, McColl E, Priest J, Bond S, Boys RJ. Newcastle satisfaction with nursing scales: an instrument for quality assessments of nursing care. Qual Health Care. 1996;5(2):67-72.

31. Alasad JA, Ahmad MM. Patients' satisfaction with nursing care in Jordan. Int J Health Care Qual Assur. 2003;16(6):279-85.

32. Akin S, Erdogan S. The Turkish version of the Newcastle Satisfaction with Nursing Care Scale used on medical and surgical patients. J Clin Nurs. 2007;16(4):646-53.

33. Walsh M, Walsh A. Measuring patient satisfaction with nursing care: experience of using the Newcastle Satisfaction with Nursing Scale. J Adv Nurs. 1999;29(2):307-15.

34. Ahmad MM \& Alasad JA. Predictors of patients' experiences of nursing care in medical- 
surgical wards. Int J Nurs Pract. 2004;10(5):235-41.

35. Peterson WE, Charles C, DiCenso A, Sword W. The Newcastle Satisfaction with Nursing Scales: a valid measure of maternal satisfaction with inpatient postpartum nursing care. $J A d v$ Nurs. 2005;52(6):672-81.

36. Chang JT, Hays RD, Shekelle PG, MacLean CH, Solomon DH, Reuben DB, et al. Patients' global ratings of their health care are not associated with the technical quality of their care. Ann Intern Med. 2006; 144(9):665-72.

37. Mahon PY. An analysis of the concept 'patient satisfaction' as it relates to contemporary nursing care. J Adv Nurs. 1996; 24(6):1241-8.

38. Cox CL. An interaction model of client health behavior: theoretical prescription for nursing. ANS Adv Nurs Sci. 1982;5(1):41-56.

39. Bear M, Bowers C. Using a nursing framework to measure client satisfaction at a nursemanaged clinic. Public Health Nurs. 1998;15(1):50-59.

40. Wagner D, Bear M. Patient satisfaction with nursing care: a concept analysis within a nursing framework. J Adv Nurs. 2009;65(3):692-701.

41. Irurita VF. Factors affecting the quality of nursing care: The patient's perspective. Int $J$ Nurs Pract. 1999;5(2):86-94.

42. Jeffs L, Beswick S, Martin K, Campbell H, Rose D, Ferris E. Quality nursing care and opportunities for improvement. Insights from patients and family members. J Nurs Care Qual. 2013;28(1)76-84.

43. Bjertnaes OA. The association between survey timing and patient-reported experiences with hospitals: results of a national postal survey. BMC Med Res Methodol. 2012;12:13. doi: 10.1186/1471-2288-12-13.

44. Brédart A, Razavi D, Robertson C, Brignone S, Fonzo D, Petit JY, et al. Timing of patient satisfaction assessment: effect on questionnaire acceptability, completeness of data, reliability 
and variability of scores. Patient Educ Couns. 2002;46(2):131-6.

45. OECD. Average length of stay: acute care. Health: Key Tables from OECD. 2013, No. 52. doi: 10.1787/1-o-s-acutecare-table-2013-2-en. 
Table 1. Factor pattern of the "Experiences of nursing" scale

\begin{tabular}{|c|c|c|c|c|c|c|c|c|}
\hline \multirow[b]{2}{*}{ Item } & \multicolumn{2}{|c|}{ Carelessness } & \multicolumn{2}{|c|}{$\begin{array}{l}\text { Emotional } \\
\text { support }\end{array}$} & \multicolumn{2}{|c|}{$\begin{array}{l}\text { Relationship } \\
\& \text { information }\end{array}$} & \multicolumn{2}{|c|}{ Caring times } \\
\hline & EFA & CFA & EFA & CFA & EFA & CFA & EFA & $\overline{\text { CFA }}$ \\
\hline Nurses favored some patients over others & .79 & .63 & .05 & & -.09 & & -.19 & \\
\hline Nurses were too easy going and laid back & .73 & .67 & -.06 & & -.01 & & -.12 & \\
\hline Nurses did not tell me enough about my treatment & .66 & .58 & .06 & & -.17 & & -.13 & \\
\hline Nurses turned the lights off too late at night & .65 & .62 & .02 & & .18 & & .09 & \\
\hline Nurses did not seem to know what I was going through & .64 & .67 & -.11 & & .03 & & -.02 & \\
\hline Nurses let things get on top of them & .54 & .72 & -.13 & & .19 & & .26 & \\
\hline Nurses did not seem to know what each other was doing & .54 & .64 & .24 & & -.19 & & .23 & \\
\hline Nurses took no interest in me as a person & .52 & .71 & -.18 & & .15 & & .22 & \\
\hline Nurses used to go away and forget what patients had asked for & .45 & .71 & -.04 & & -.12 & & .24 & \\
\hline I saw the nurses as friends & -.01 & & .84 & .76 & .05 & & .15 & \\
\hline No matter how busy nurses were, they made time for me & -.11 & & .73 & .69 & -.02 & & .10 & \\
\hline Nurses spent time comforting patients who were upset & .07 & & .62 & .72 & .18 & & .01 & \\
\hline It was easy to have a laugh with the nurses & -.08 & & .59 & .63 & .00 & & -.01 & \\
\hline Nurses gave me information just when I needed it & .05 & & .49 & .63 & .07 & & -.20 & \\
\hline Nurses told the next shift what was happening with my care & .06 & & .32 & .63 & .29 & & -.17 & \\
\hline Nurses made sure that patients had privacy when they needed it & -.04 & & -.13 & & 68 & .60 & -.06 & \\
\hline There was a happy atmosphere in the ward, thanks to the nurses & -.13 & & .23 & & .63 & .78 & .16 & \\
\hline Nurses knew what to do for the best & -.03 & & .07 & & .60 & .64 & .02 & \\
\hline Doctors and nurses worked well together as a team & .03 & & .09 & & .56 & .64 & -.05 & \\
\hline Nurses explained what they were going to do to me before they did it & .12 & & .22 & & .38 & .62 & -.19 & \\
\hline Nurses explained what was wrong with me & .10 & & .19 & & .33 & .54 & -.16 & \\
\hline Nurses checked regularly to make sure I was okay & -.02 & & .01 & & .03 & & .61 & .57 \\
\hline Nurses knew what to do without relying on doctors & .06 & & .15 & & -.11 & & .47 & .46 \\
\hline Nurses took a long time to come when they were called & .10 & & .20 & & .02 & & -.42 & -.48 \\
\hline Nurses had time to sit and talk to me & .14 & & .01 & & -.08 & & .38 & .56 \\
\hline Nurses made me do things before I was ready & .02 & & -.03 & & .03 & & -.34 & -.32 \\
\hline Factor score determinacy coefficients & & 4 & & 94 & & 93 & & 86 \\
\hline Cronbach's alpha & & 37 & & 81 & & 80 & & 60 \\
\hline
\end{tabular}

EFA: Exploratory Factor Analysis

CFA: Confirmatory Factor Analysis 
Table 2. Factor pattern of "Satisfaction with nursing" scale

\begin{tabular}{|c|c|c|}
\hline Item & EFA & CFA \\
\hline Nurses' awareness of your needs & .88 & .77 \\
\hline Nurses' helpfulness & .87 & .79 \\
\hline How willing nurses were to respond to your requests & .86 & .83 \\
\hline Nurses' manner in going about their work & .86 & .78 \\
\hline How nurses helped put your relatives' or friends' minds at rest & .86 & .82 \\
\hline How often nurses checked to see if you were ok & .86 & .84 \\
\hline The way nurses explained things to you & .85 & .82 \\
\hline Nurses' treatment of you as an individual & .85 & .86 \\
\hline The way the nurses made you feel at home & .84 & .87 \\
\hline The amount of privacy nurses gave you & .84 & .85 \\
\hline The amount of information nurses gave to you about your condition and treatment & .83 & .85 \\
\hline There always being a nurse around if you needed one & .83 & .86 \\
\hline The type of information nurses gave to you about your condition and treatment & .82 & .81 \\
\hline How quickly nurses came when you called for them & .81 & .85 \\
\hline How capable nurses were at their job & .80 & .84 \\
\hline The amount nurses knew about your care & .78 & .76 \\
\hline The amount of time nurses spent with you & .77 & .86 \\
\hline The amount of freedom you were given on the ward & .77 & .84 \\
\hline How nurses listened to your worries and concerns & .74 & .88 \\
\hline Factor score determinacy coefficient & \multicolumn{2}{|c|}{.99} \\
\hline Cronbach's alpha coefficient & \multicolumn{2}{|c|}{.98} \\
\hline
\end{tabular}

EFA: Exploratory Factor Analysis

CFA: Confirmatory Factor Analysis 
Table 3. Correlations between factors and overall ratings

\begin{tabular}{llll}
\hline & Satisfaction & $\begin{array}{l}\text { Overall satisfaction } \\
\text { with nursing }\end{array}$ & $\begin{array}{l}\text { Overall satisfaction } \\
\text { with hospital }\end{array}$ \\
\hline Carelessness & -.478 & -.387 & -.390 \\
Emotional support & .724 & .692 & .654 \\
Relationship and information & .598 & .541 & .537 \\
Caring times & .125 & .153 & .158 \\
Satisfaction & 1 & .816 & .772 \\
\hline
\end{tabular}

Most items of the factor Carelessness were negative statements, which were not reversed

All correlations were significant at $\mathrm{p}<0.01$ 